\section{CORPO NO PRAGMATISMO DE RICHARD RORTY}

BODY IN RICHARD RORTY'S PRAGMATISM

CUERPO EN EL PRAGMATISMO DE RICHARD RORTY

Fernando Garcez de Melo*, Evando Carlos Moreira**
Palavras chave:

Corpo.

Educação física.

Pragmatismo.

Epistemologia.
Keywords:

Body.

Physical education.

Pragmatism.

Epistemology.

Palabras clave:

Cuerpo.

Educación Física.

Pragmatismo.

Epistemología.
Resumo: O valor atribuído às expressões atividade física ou práticas corporais guarda estreita relação com o referencial epistêmico que possuem acerca do corpo, incidindo sobre a própria Educação Física (sua especificidade). Considerando as implicações que o corpo gera para a Educação Física, exploramos neste ensaio a noção de corpo no pragmatismo de Richard Rorty (1931-2007). O objetivo é compreender a perspectiva rortyano-pragmática de corpo e suas implicações para a Educação Física. Dentre outros aspectos, nossa leitura sugere compreender o corpo como contingente e não admitindo fins teleológicos, deixando em aberto para exploração e redescrições. A implicação para a Educação Física é a ênfase nos critérios sociais e políticos (e não epistemológicos e ontológicos) para a criação de ações e pensamentos mais profícuos para a realização da educação corporal.

Abstract: The value ascribed to the expressions physical activity or bodily practices connects intimately to their epistemic reference about the body, focusing on physical Education itself - its specificity. Considering the implications that the body creates for Physical Education, this essay explores the notion of body in the Pragmatism of Richard Rorty (1931-2007) to understand the Rortyan-pragmatic perspective on the body and its implications for Physical Education. Among other aspects, our reading suggests understanding the body as contingent and not admitting teleological purposes, leaving it open to exploration and re-descriptions. The implication for Physical Education is the emphasis on social and political - rather than epistemological and ontological - criteria for creating actions and thoughts that are more fruitful for bodily education.

Resumen: El valor atribuido a las expresiones actividad física o prácticas corporales guarda estrecha relación con el referente epistémico que poseen en cuanto al cuerpo, e incide sobre la propia Educación Física (su especificidad). Considerando las implicaciones que el cuerpo genera para la Educación Física, exploramos en este ensayo la noción de cuerpo en el pragmatismo de Richard Rorty (1931-2007). El objetivo es comprender la perspectiva rortyana-pragmática de cuerpo y sus implicaciones para la Educación Física. Entre otros aspectos, nuestra lectura sugiere comprender el cuerpo como contingente, sin admitir fines teleológicos, dejando el tema abierto para exploración y redescripciones. La implicación para la Educación Física es el énfasis en los criterios sociales y políticos (y no epistemológicos y ontológicos) para la creación de acciones y pensamientos más fructíferos para la realización de la educación corporal.
*Universidade do Estado de Mato Grosso (UNEMAT). Cuiabá, MT. Brasil

E-mail:

garcez@unemat.br

**Universidade Federal de Mato Grosso (UFMT). Cuiabá, MT. Brasil. E-mail:

ecmmoreira@uol.com.br

Recebido em: 08-07-2019 Aprovado em: 23-03-2020 Publicado em: 27-04-2020 (c) (1) (8) Licence 


\section{INTRODUÇÃO}

A ideia de filosofia-enquanto-epistemologia nos forneceu um modo de olhar e compreender o mundo, tendo como um de seus aspectos subjacentes a relação sujeito-objeto. Um dos usos dessa relação manifesta-se, nas diversas áreas de conhecimento, na tentativa de identificar ou revelar o próprio objeto da área, que servirá como referência para a sua construção e desenvolvimento. Todavia, particularmente no século XX, nem todos aquiesceram perante essa imagem: Richard Rorty (19312007), filósofo estadunidense, foi ao menos um deles. Em oposição a essa ideia, defendeu a tese de que deveríamos parar de utilizá-la, mas visto o enraizamento tanto da noção de epistemologia quanto da relação sujeito-objeto no vocabulário moderno, pode ser difícil vislumbrar as mudanças em que incorreriam, por exemplo, no cenário da educação física. E é este cenário que pretendemos explorar.

O nosso pano de fundo será o esforço presente na educação física em tentar, calcado na relação sujeito-objeto, encontrar ou delimitar o seu objeto. Nossa estratégia não será de retomar esse debate, mas de nos dedicarmos a um assunto o corpo. Genericamente, a justificativa para essa estratégia assenta-se (1) na "virada epistemológica" inaugurada por René Descartes (1596-1650) e sua postulação do dualismo mente-corpo, (2) a institucionalização da educação física em idos do século XIX, na condição de disciplina escolar, como meio de promover a então educação physica (PAIVA, 2003) que junto com a educação intelectual e moral formavam o tripé da educação integral do ser humano, e (3) como assinala Soares (2012, p. 41), "O corpo, do qual [a educação física] se ocupa, é o corpo anatomofisiológico. E ele será a referência fundamental de seu desenvolvimento como prática social".

O presente ensaio toma como pertinente e dá continuidade as considerações anteriores acerca dessa relação entre a noção de corpo e o objeto ou saber específico da educação física, ou seja, de que uma noção de corpo incide ou atrela-se ao saber específico da área e, por conseguinte, incide na ação pedagógica do professor. $\mathrm{O}$ debate envolto nessa relação ou, mais comumente, em torno do objeto ou saber específico da educação física, como debatido nos trabalhos de Betti (2009) e Bracht (1999a), resultou em tentativas de definição de um conceito da educação física (escolar), justificando que assim teríamos um ponto de origem para desenvolver nossas ações científicas e/ou pedagógicas. E cada definição podia remeter a um conjunto próprio de princípios e orientações a fim de tornar a área crítica, emancipadora ou plural, contudo não raro inconciliáveis. O valor desse debate assenta-se sobre a possibilidade de vislumbrarmos novos modos para efetivar a educação corporal (expressão que ganhará sentido no decorrer do texto).

A escolha pelo pragmatismo de Richard Rorty (1931-2007) deve-se ao campo de possibilidades aberto ao expor um embaraçoso cenário legado pelo projeto filosófico centrado na epistemologia e sua teoria representacionalista, e ao desenvolvimento de uma perspectiva não representacionalista de conhecimento, realçando, portanto, a atividade do ser humano de usar e criar diferentes vocabulários/descrições para lidar com o mundo. Esses vocabulários podem ser comparados uns aos outros a fim de estabelecer, para uma específica situação, qual é mais-menos útil ou inútil, mas 
nenhum podendo ser posto como correspondendo com a realidade (ou expressões que venham a assumir um caráter definitivo e restritivo para a conversação). Desse modo, lidamos com o próprio pragmatismo como mais um desses vocabulários, o qual exploramos nesse ensaio com o objetivo de compreender a perspectiva rortyanapragmática de corpo e suas implicações para a educação física.

Vale ressaltar os desafios que serão enfrentados nessa trajetória, visto não ser recorrente que Rorty trate do assunto corpo, e quando o faz não é detidamente como o fazem os filósofos Maurice Merleau-Ponty ou Richard Shusterman. Assim, nossa primeira tarefa é identificar sua noção de corpo e contextualizá-la, isto é, traçar conexões com outros aspectos de sua perspectiva pragmática. Outro desafio é justamente o de traçar essas conexões, visto sua ampla produção estar envolta em diversos aspectos, tais como a mente, o eu, a epistemologia, a teoria da verdade, as redescrições. No que segue, ofereceremos nesse ensaio a nossa descrição sobre o corpo ao lermos a obra de Rorty. O resultado não é mais do que uma visão panorâmica.

\section{CORPO NUMA PERSCPECTIVA PRAGMÁTICA}

É difícil mencionar corpo sem tentar fazer um contraste com mente. Em boa parte, isso se deve ao vocabulário que herdamos de René Descartes e continuado, guardadas as peculiaridades, por Locke, Leibniz, Hume e Kant ${ }^{1}$. Antes desse vocabulário cartesiano, registraremos tão somente a observação de Rorty de que a ideia de apreensão de universais preparou o terreno para que Descartes fizesse sua proposição: a de que o ser humano é composto por duas substâncias distintas - mente e corpo, res cogitans e res extensa, imaterial e material (RORTY, 1994). Mais do que uma distinção, foi estabelecida uma hierarquia valorativa entre elas, atribuindo ao primeiro termo dos pares maior valor, ou num sentido mais forte, o único com valor. E a educação física ao se sustentar no corpo - algo simples (e não complexo), efêmero (e não eterno), meramente físico (e não expressando o "algo a mais" do ser humano) - se encontra desvalorizada (BRACHT, 1999b). A reação frequente ao cartesianismo é a de tentar abandonar o seu dualismo de substância, como podemos notar nos profícuos trabalhos de Sant'Anna (2006), Ortega (2008) e Silva (2011), embora ainda com reminiscências do dualismo. Todavia, Appiah (2006) chama a atenção explicitamente, e Rorty (1994) de modo semelhante, para a questão epistemológica inaugurada por Descartes e, secundariamente, para a questão ontológica presente no referido dualismo. Ou seja, o dualismo é um subproduto do método investigativo cartesiano e, resolver isso, é apenas meio passo para um novo método de investigação. Dito de outra forma, não se desvencilha do dualismo completamente ao se manter o pressuposto epistemológico, isto é, a existência de um campo comum prévio em que se funda o conhecimento Isto gera uma série de dualismos, como sujeito-objeto, aparência-realidade, essência-existência, forma-

1 Como explica Silva (2012, p. 511): "Para ele [Rorty], a filosofia do sujeito de Descartes é o ponto de partida para um projeto, posteriormente continuado de diferentes maneiras por Locke, Leibniz, Hume e Kant, que visa tornar a epistemologia a área central da filosofia e, com isso, fazer da mesma uma atividade privilegiada cujo objetivo seria não a busca da sabedoria e sim a busca da verdade que, por sua vez, permitiria fundamentar e legitimar as demais áreas do conhecimento (como a ciência, a literatura, a política, a arte, a religião, a educação, a moral etc.) ou, pelo contrário, fragilizar as mesmas através da não ratificação de suas asserções sobre o conhecimento". 
conteúdo e, reiteramos, mente-corpo. Ao nosso ver, ao combater o dualismo mentecorpo e mantendo os demais dualismos, a educação física, por meio dos autores de diversas áreas (filosofia, sociologia...) que frequentemente embasaram os estudos de nossa área, fez apenas parte do caminho. Veremos como Rorty lida com essa questão epistemológica e adiante qual diferença isso faz na noção de corpo e para a educação física.

René Descartes em seu método de investigação almeja obter o elemento indubitável, seu procedimento é o de pôr as coisas em dúvida até encontrar algo do qual não poderia mais fazer isso, em suma, a mente. O desdobramento dessa perspectiva, que Rorty expõe e contesta, é o chamado representacionalismo: a crença de que a verdade ou a mente correspondem ao mundo; o ser humano como sendo capaz de representar o mundo tal como ele é. Posteriormente, ao longo da história, predominantemente ocorreu apenas uma atualização, trocando mente por outras substâncias ou universais (ou ingrediente extra, como ironicamente Rorty se refere), tais como a consciência. Um exemplo, mais familiar para nós da área educacional, é o materialismo, com destaque para o marxismo, que endossa a noção de verdade como correspondência, visto o apreço que possuem pela ideia de que os "objetos existem independentemente ao ser humano". Os objetos estão aí, prontos para serem apreendidos. Cabe então utilizar o método adequado para captar o elemento inerente ou a essência do objeto. É emblemático o caso marxista, pois embora use a dialética e a história, as mantém subsumidas a um materialismo reducionista ${ }^{2}$ definidor do determinante último.

Como mostram Almeida e Vaz (2013, p. 258), há uma confusão entre a pergunta "como identificamos objetos?" com a pergunta "antecedem os objetos a nossa identificação?”. Rorty não dúvida que os objetos ou eventos ou fenômenos, em suma, as coisas em geral, antecedem a nossa identificação, mas não encontra justificativa plausível para afirmarmos que os seus significados estavam previamente definidos antes de realizarmos descrições sobre eles. As coisas - montanhas, gravidade, girafas, o próprio corpo - só têm significados a partir de nossas descrições e relacionadas a um contexto. Por isso, Rorty não endossa o modelo representacionalista, em que algo não-linguístico dita o linguístico. Estas são teses de Donald Davidson (1917-2003) que Rorty adota. Com elas, quer mostrar que o uso dos vocabulários físico e mental são igualmente utilizáveis, devendo ser avaliados pela utilização num específico contexto. Rorty assume uma posição antirrepresentacionalista, o que equivale a abandonar a noção de mente, consciência e outras expressões que remetam a um ingrediente extra que permita ao ser humano ser racional.

Após essa sinóptica descrição de como Rorty lida com a epistemologia, passaremos a nos dedicar a um de seus textos que, em nossa leitura, nos fornece bons elementos para compreendermos e elucidarmos sua noção de corpo: Fisicalismo nãoredutivo (RORTY, 1997). De pronto, adiantamos que um dos aspectos aparentemente mais difíceis, não é exatamente a própria noção de corpo, mas o cenário de fundo em que se situa. Como mencionado antes, o dualismo sujeito-objeto se apresenta como uma das facetas do representacionalismo. Neste texto, Rorty apresenta algumas

2 Para Rorty (1997, p. 169-170), reducionismo é a "tentativa de encontrar uma linguagem singular o suficiente para estabelecer todas as verdades que há para serem estabelecidas". 
problemáticas presentes nela e oferece uma redescrição, donde depreendemos sua noção de corpo. Importante ter em consideração que, paulatinamente, apresenta-se uma refutação ao dualismo e a assunção do monismo. E, de modo complementar, que isso não significa ir pela via reducionista.

Para expressar seu entendimento, Rorty (1997) apresenta um modelo (figura 1) que ilustra o sujeito pós-kantiano. Em resumo, o que ele quer mostrar nesse modelo é que "[...] a maior parte da filosofia desse período consistiu em tentar especificar a relação entre os três âmbitos desse Si próprio, tanto quanto a relação de cada um desses âmbitos com a realidade física" (Rorty, 1997, p. 163). Este sujeito é composto por três camadas: o eu $u^{3}$ externo (formado por crenças e desejos "contingentes" e "empíricos"); o eu médio (formado por crenças e desejos "necessários", "estruturais"); e o eu interno/verdadeiro (é o domínio do inefável, do não-linguístico. Nele contém o que "são" crenças e desejos).

Figura 1 - Relação eu-mundo no modelo pós-kantian

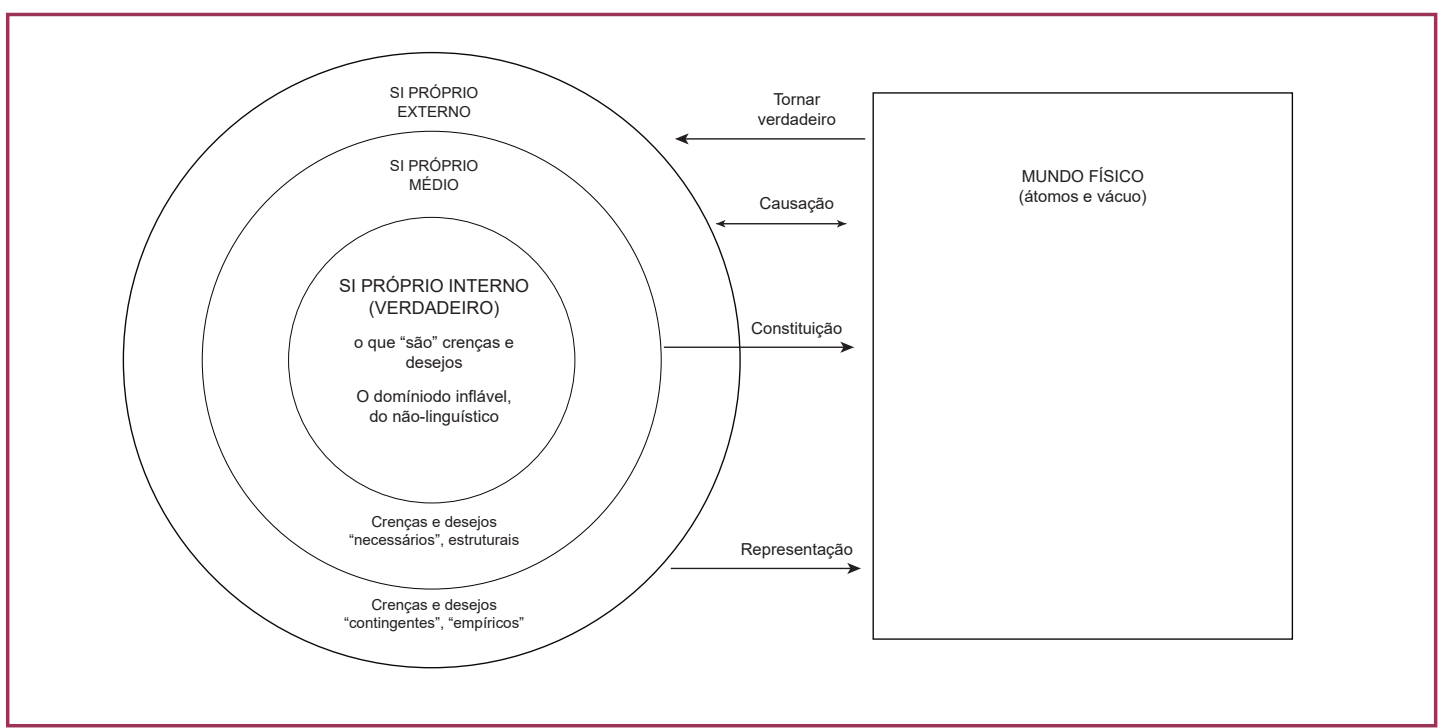

Fonte: Rorty (1997, p. 165).

Este modelo (figura 1) é usado para explicar a relação eu-mundo/sujeitoobjeto (nele o corpo está no polo do mundo e não do eu), que ocorre das seguintes maneiras: entre o eu externo e o mundo de três modos: um deles é quando o mundo "torna verdadeiro" o eu externo; outro é quando o eu externo "representa" o mundo; por fim, a sugestão de Rorty, que há uma relação de causação entre eu externo e o mundo. Além dessas três, há uma relação em que o eu médio "constitui" o mundo. O que Rorty faz nesse trabalho é mostrar como podemos retirar cada uma das setas, deixando apenas a da "causação".

Desse modelo na figura 1, enfatizamos o seu dualismo-duas coisas irredutíveis uma à outra: um polo com entidades mentais (eu externo, médio e interno), outro polo com as entidades físicas (o mundo e o próprio corpo); um polo é o sujeito, coisa pensante, o outro polo, são os objetos sobre os quais pensamos a respeito, as coisas 
materiais. Uma situação simplória ilustra o que se passa - trata-se do sujeito (você, leitor) defronte ao mundo se perguntando: "estou vendo o mundo como ele realmente é?" Ou "o que estou vendo é realmente aquilo que penso que é?" Em especial, a segunda pergunta, é esclarecedora por instigar uma suspeita. Ou seja, pode ser que o sujeito esteja enganado sobre o que está vendo. A forma tradicional de transpor esse "engano" ou "ilusão", sair da aparência para a realidade, é recorrer à algo do domínio do inefável, do não-linguístico. A mente cartesiana é um exemplo do que, na figura 1, ocupa o eu interior. Sua tarefa é a de verificar se àquilo que está no mundo corresponde as suas próprias representações. Essa ideia de representação é derrubada pela adoção da crença como hábitos de ação ${ }^{4}$, de Peirce.

Vale notar que o quase total abandono do dualismo de substância de Descartes não significou o mesmo com a relação sujeito-objeto, embora com um detalhamento e enriquecimento heurístico muito maior. $\mathrm{O}$ desejo de saber como representar o mundo lá fora, tornou-se até mesmo intuitivo. Denominar de "histórico" ou "cultural" concomitantemente ao pressuposto da relação sujeito-objeto é, em maior ou menor grau, manter a visão representacionalista, a visão de nos aproximarmos da representação acurada ou da realidade ou da objetividade.

$\mathrm{Na}$ sequência discute a conexão entre o eu médio e o mundo, que afirma a existência de crenças e desejos "necessários" que constituem o mundo. O que se coloca aqui, inicialmente, é a distinção entre camada externa e a média, correspondente à distinção assinalada por Willard Quine (1908-2000) entre verdades necessárias/estruturais e verdades contingentes. Esta distinção consiste em afirmar que assertivas como "2+2=4" são verdades "necessárias" por prescindirem do mundo empírico, e que assertivas como "temos duas bolas de futebol" são verdades "contingentes" por requererem o mundo empírico para sua comprovação. No primeiro caso, tem-se verdades a priori, que independem do ser humano. Enquanto que, no segundo caso, para a assertiva "temos duas bolas de futebol" ser verdadeira é necessário verificar empiricamente a existência das bolas, e por isso, no modelo póskantiano, são verdades contingentes.

Essas duas "verdades" são distinguidas em espécie, e não em grau (uma distinção qualitativa, e não quantitativa) dentro do modelo. Algo similar ao dualismo mente e corpo, mas atualizado. Afirma-se ser atualizado, pois a abordagem introspectiva de Descartes, por exemplo, se mantém. A verdade necessária é algo que se obtêm por introspecção, autorreflexão, é um olhar sobre si, da primeira pessoa. Quine, e também Rorty, adotam a perspectiva da terceira pessoa e passam a privilegiar o comportamento da pessoa. E fazem isso em virtude da crítica do segundo Wittgenstein à linguagem privada. Ao adotar a terceira pessoa e a atenção sobre o comportamento da pessoa, Quine mostra como torna-se infrutífero a distinção em espécie, embora se mantenha a distinção em grau. Isto é, há asserções em que um indivíduo tem mais dificuldades em abrir mão, como "2+2=4", enquanto asserções como "temos duas bolas de futebol" são mais fáceis de serem descartadas. Desse modo, não temos a separação entre o eu externo e o eu médio, que remetia à uma 
camada mais profunda "constituída" por verdades "necessárias" e outra camada mais superficial com verdades "contingentes".

Valendo-se das ideias de Davidson, Rorty apaga a seta "tornar verdadeiro", que vai do mundo para o eu externo (que é o caminho oposto ao da representação) A premissa não se altera, mas agora o mundo que fornece as propriedades objetivas sobre às quais podemos encontrar um único vocabulário para descrevê-las. Por isso significa que o mundo "torna verdadeira" nossas asserções.

Isto é diferente do que Rorty (1997, p. 166) propõe:

\begin{abstract}
Essa extinção equivale a dizer que se nós tivermos relações causais (como essas entre a abertura de uma porta e a aquisição de crenças) se sustentando entre o mundo e o Si próprio [eu], tanto quanto relações de justificação ("ser uma razão para") internas à rede de crenças e desejos do Si próprio, nós não necessitaremos de nenhuma relação ulterior para explicar como o Si próprio entra em contato com o mundo, e vice-versa.
\end{abstract}

Essa passagem resume a perspectiva de Rorty, para o qual o que há são relações causais entre o mundo e o eu, tanto quanto relações de justificação. Para usar seu exemplo, quando abrimos uma porta podemos adquirir várias crenças como, por exemplo, "vejo luz". A crença, no exemplo numa descrição mental, adquirida ao abrir a porta se justifica se "há luz", no sentido de que "luz" é um termo criado com o sentido de "está claro" e fazer um contraste com "sem luz" ou "está escuro". Havendo consonância entre a crença e a justificação, podemos afirmar que temos uma crença verdadeira justificada. Uma descrição física de "luz" como "toda radiação eletromagnética sensível à visão humana e cujos comprimentos de onda estão contidos na faixa entre $400 \mathrm{e}$ 740 nanômetros aproximadamente" (HOUAISS, 2009) $)^{5}$ não a "torna verdadeira", mas apenas descrita de outro modo, e mais útil a depender do contexto.

Diferentemente, aquele que endossa a ideia de que o mundo "torna verdadeira" as coisas, entende que falta algo na explicação anterior. Primeiro, negando que "luz" seja algo criado, pois tal fenômeno ótico existe independentemente do ser humano. Segundo, afirmar que "vejo luz" requer não uma consonância com o entendimento realizado por um determinado público (pressuposto intersubjetivo), mas com a "realidade". O pragmático não consegue encontrar sentido na expressão "realidade" fora de um vocabulário. E seja o que for definido por "realidade", só é passível de compreensão e de ser criticável, uma vez descrito.

Ao final, o que temos é uma relação causal entre o ser humano individual e o resto do universo, entre corpo e mundo. Em seu modelo fisicalista não-redutivo (figura 2), Rorty (1997, p. 166) explica:

\footnotetext{
A distinção entre o Si próprio [eu] e o mundo foi substituída pela distinção entre o ser humano individual (descritível em termos tanto mentais quanto físicos) e o resto do universo. A primeira distinção [o ser humano individual] é delimitada pelos contornos do corpo, e a tarefa de explicar as relações entre eventos ocorrentes no interior dessa fronteira e todos os outros eventos é uma questão de postular, ou observar, entidades no interior desse contorno: causas internas do comportamento do ser humano. Essas causas incluem tanto itens macroestruturais quanto microestruturais, tanto mentais quanto físicos: entre eles estão os hormônios, pósitrons, sinapses neurais, crenças, desejos, ânimos, enfermidades e múltiplas personalidades.
} 
Figura 2 - Relação eu-mundo no modelo fisicalista não-redutivo

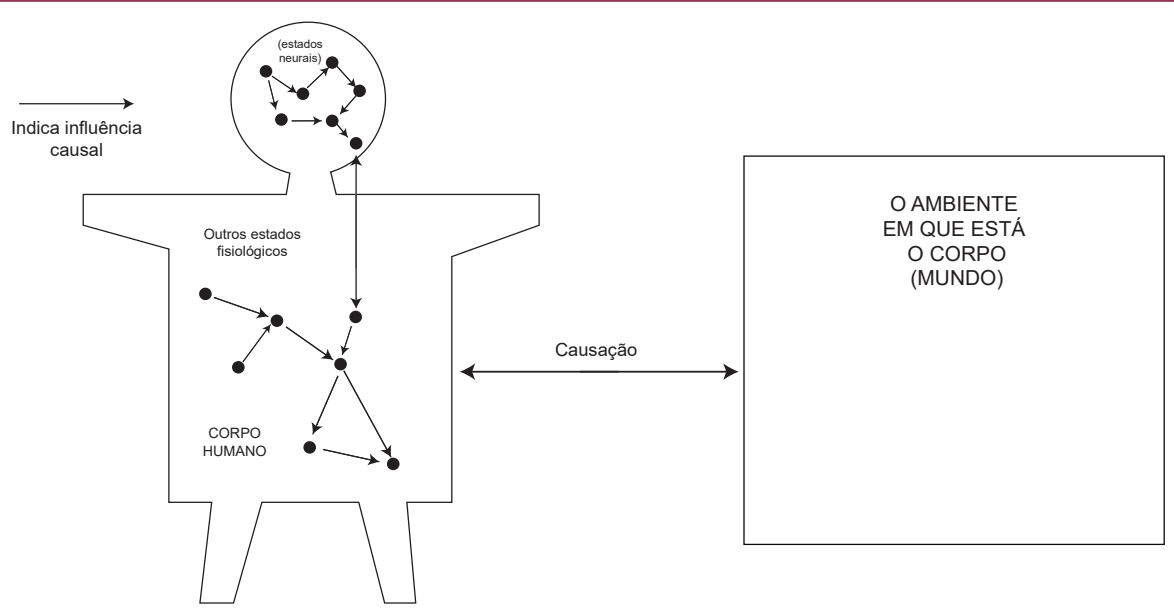

Fonte: Rorty (1997, p. 167).

Uma consequência que podemos retirar dessa redescrição rortyana acerca da relação eu-mundo, é o seu abandono da tradicional relação sujeito-objeto, portanto, em termos ontológicos, não temos mais a relação entre entidades não-físicas e físicas, mas uma relação entre entidades físicas. Com isso, passamos a utilizar a noção de causação (ou teoria causal de conhecimento) para a explicação das relações. Tal teoria consiste, grosso modo, em postular ou observar as causas/razões em relação com seus efeitos ${ }^{6}$. Depreendemos do modelo rortyano que somos o nosso corpo, no sentido orgânico, natural, como bípedes sem penas, todavia desinvestido da áurea representacionalista e reducionista. Um corpo contingente. Noutro sentido, o representacionalista descreve o corpo como meramente físico no sentido de não ter mente, ser irracional. Reduz o corpo a mero suporte de "algo a mais". Precisamente por isto não avançam (tanto quanto podiam) em relação ao dualismo cartesiano e neokantiano, por ainda não reconhecerem o corpo na realização do pensamento e da racionalidade sem postularem um ingrediente extra. $\mathrm{O}$ corpo naturalizado pelo pragmatismo é o que desenvolveu as habilidades de pensar e ser emotivo. Aliás, está aberto a criação por homens, mulheres e LGBTI+ ${ }^{7}$, e não mais como algo a ser descoberto. É o nosso corpo que faz discursos como o de Martin Luther King, canta como Freddie Mercury, luta pelas mulheres como Judith Bluter. Não há denominador comum ou múltiplos fatores a serem sintetizados e que revelam o eu verdadeiro, ou algo no mundo que "torna verdadeiro" nossas características.

Essa perspectiva naturalista também é diferente do que Rorty chama de platonismo às avessas - "a tentativa romântica de enaltecer a carne em relação ao espírito, o coração em relação à mente, e uma faculdade mítica chamada 'vontade' em relação a outra, igualmente mítica, chamada 'razão (RORTY, 2007, p. 73). Aspecto que não foi possível desenvolver nesse ensaio.

O corpo ainda que desinvestido de uma ontologia é habilitado a criar descrições de si. Não tendo espírito, alma, substância ou ingrediente extra que 
acenda a chama da vida consciente, a habilidade de descrever a si mesmo, assim como as outras ações realizadas pelo corpo, são habilidades desenvolvidas ao longo do processo evolutivo/cultural. A faculdade que o torna mais complexo é a imaginação ou, seguindo a leitura de Freud por Rorty (2007, p. 78), "é a faculdade de criar metáforas". Entretanto, diferente da racionalidade substancializada (ou como ingrediente extra), a imaginação enquanto capacidade de criar metáforas não nos remete a uma "consciência moral comum", mas tão somente a capacidade de uma pessoa se valendo de seu vocabulário final, já literalizado, o combine com novas crenças e crie metáforas, no sentido dado por Davidson ${ }^{8}$. Nesse sentido, o corpo pode ser descrito sob dois aspectos: eu e organismo, ou, numa versão didática nossa, trata-se do corpo (organismo) e as suas ações (o eu), por isso não há ingrediente extra. Estes aspectos são tão somente dois modos incomensuráveis de o descrever, pois, com base no monismo anômalo de Davidson, a tese reducionista de que todas as nossas ações poderiam, sem problemas, ser descritas em termos físicos (ou algum vocabulário único) não se sustenta. Utilizar um vocabulário mental não permite inferir uma ontologia com entidades mentais. Se digo "Paulo Freire é brilhante" estou a utilizar uma asserção dentro de um vocabulário mental (ou psicológico) por descrever um comportamento - agir com brilhantismo ou capacidade intelectual distintiva - não por suas características e processos físicos (o funcionamento da rede neural, etc.), mas pelo modo como o sujeito se relaciona com o mundo.

Outrossim, o eu não é "algo a mais" do que o organismo porque aprendemos a descrever a nós mesmos como emotivos, criativos, estúpidos, preconceituosos, adoradores de deuses, apaixonados por futebol ao invés de nos identificarmos com nossos órgãos internos ou os estados físicos em que se encontram ${ }^{9}$. O eu não é uma representação interna. O eu coincide com nossa rede de crenças e desejos, e "essas crenças e desejos são, é certo, estados fisiológicos sob outra descrição" (RORTY, 1997, p. 168). Esta frase explicita como Rorty não se vê como dualista, embora não impeça que forneçam sobre ele outras descrições. Por fim, nessa redescrição e imagem (figura 2) o eu diferencia-se do "eu por camadas" (figura 1), e expressa seu constante entretecer em crenças e desejos até que o corpo pereça.

\section{IMPLICAÇÕES DA PERSPECTIVA RORTIANA SOBRE O CORPO NA EDUCAÇÃO FÍSICA}

O caminho percorrido anteriormente assinala a estratégia terapêutica e não sistemática de Rorty, a tentativa de limpar o terreno, e não de fundar um programa de investigação ${ }^{10}$. Esse modo terapêutico de filosofar serviu para afastar certas perspectivas representacionalistas sobre o corpo, como o cartesianismo e o pós-kantismo, e que o reduzem a um aspecto em particular. Obviamente,

\footnotetext{
8 Metáfora, para Davidson, faz contraste com literal em seu vocabulário, é quer dizer uma frase sem lugar fixo num jogo de linguagem, ou até mesmo uma frase sem sentido. Ele quer ilustrar como frases novas surgem em nosso vocabulário, e precisamente por isso demanda atribuições de valor pelos usuários da linguagem. Em Silva Filho (2001) há uma elucidação específica desse item.

9 Para maior aprofundamento e evitar confusão entre o pensamento historicista de Rorty e atomistas como Steven Pinker, consultar o texto Holismo e historicismo (RORTY, 2009).

10 Como mostra Appiah (2006, p. 64), a fundação de um programa de investigação é típica das epistemologias fundacionalistas, para as quais "precisamos encontrar alguma categoria de crenças sobre as quais temos conhecimento seguro".
} 
representacionalistas tendem a se autodescreverem ou se autoproclamarem como descobridores da fonte desencadeadora de todas as potências ou vontades humanas, por vezes até emancipadoras. Na descrição representacionalista, o corpo precisa ser dotado de um ingrediente extra para, então, sair do reino da necessidade para o reino da liberdade. Rorty vê essas perspectivas como narrativas que cumpriram um específico papel no curso da história, tendo sido útil para determinados propósitos. Mas, que agora podem ser substituídas, cabendo aos seres humanos inventarem novas narrativas para os problemas que surgem (a utopia de Rorty é a de que podemos criar um mundo melhor, e não que chegaremos a um porto seguro).

Desse modo, chegamos a um corpo ontologicamente neutro, no sentido de que ele, sozinho, não nos ajuda a decidir a qual cultura devemos participar ou desenvolver ou o que fazer. A vantagem dessa descrição é a de podermos criar um sem-fim de narrativas que podem ser razões para as suas ações. O processo passa a ser fundamentalmente educacional, de busca por novas e melhores formas de combinar as culturas.

Da noção de corpo depreendida de Rorty, enfatiza-se o abandono das noções tradicionais de mente, de consciência e, inclusive, de linguagem ${ }^{11}$, como algo que nos habita, embora não seja negada a possibilidade de redescrição desses termos. Ao realizarmos o abandono daquelas noções tradicionais, nossa atenção volta-se para o corpo (organismo) e suas ações (o eu). Uma das implicações é a de postular que toda educação é educação corporal, e evitar aquela distinção assinalada por Soares (2014) entre "educação em geral e educação do corpo especificamente", pois passa a impressão de termos uma educação intelectual (ou cultural) em oposição a uma educação do corpo (tratada como meramente física ou potência oprimida). Agora, uma vez admitida que toda educação é corporal, é como se incorresse em tautologia na linguagem ordinária, o que nos permite não usar o adjetivo "corporal" junto com a expressão "educação". Desde que se tenha implícito a referência corporal.

Qual é, então, a especificidade da educação física nessa perspectiva? Seja qual for ela advém da história, da sociologia, da antropologia; e mais, está relacionada a propósitos ou objetivos, e não a um objeto. O contraste que desejamos fazer é de que, embora a relação sujeito-objeto nos tenha sido útil, inclusive no desenvolvimento do historicismo, ainda mantém resquícios da busca por uma essência. A noção de objeto implica na crença de que há algo de intrínseco nas coisas, e quando essa noção foi expandida por sobre o próprio sujeito, começou-se a acreditar que nós, humanos, possuímos algo intrínseco, enquanto no antirepresentacionalismo nos contentamos com a afirmação de que o significado de algo é o seu uso.

Desse modo, não descrevemos a educação como a busca pelo seu objeto para, por conseguinte, traçar os modos próprios de a realizar. Para ilustrar, vejamos a obra de Saviani (2005), que inicia sua proposta histórico-crítica afirmando que "[...] a compreensão da natureza da educação passa pela compreensão da natureza humana. [grifo nosso]" Sabemos que, para Saviani, "A natureza humana não é dada ao homem mas é por ele produzida [...] [grifo nosso]", e estaria aí seu substrato

11 Embora não tenhamos nos dedicado a esse ponto, vale registrar que Rorty também se opõe a ideia de uma linguagem no sentido universal (RORTY, 2007). 
histórico, ocorre que ele termina a frase afirmando "[...] por ele produzida sobre a base da natureza biofísica [grifo nosso]". E esta última "natureza biofísica" pode ser captada em sua essência ou objetividade. Esse é um tipo de resquício essencialista e de objetividade que Rorty combateu ${ }^{12}$.

Em contraste, nos concentraríamos em explorar os diferentes modos de a realizar, ou seja, nas educações.

Por essa via, podemos dizer que as educações advêm não de elementos inerentes, mas de um conjunto de ações e pensamentos bem justificados para a coletividade. Elas serão tantas quantas as áreas da cultura em que se deseja socializar os indivíduos: educação intelectual, corporal, moral, sexual, musical, política, entre outras, e estão num plano horizontal e entrecortadas. No caso da educação física, é cessar a tentativa de delimitar um objeto, isto é, a tentativa de restringir seu campo de inquirição e ação, direcionando sua atenção para as intenções, os objetivos ou as propostas educacionais que almejam concretizar a educação corporal.

A essa altura, poderia transparecer que estamos propondo o corpo como objeto da educação física, o que seria incorreto. Ter algo como objeto, como o corpo, requer admitir a tese representacionalista de que ele possui propriedades inerentes. $\mathrm{Na}$ descrição pragmática, não estamos postulando nada que seja propriedade inerente ao corpo. Por isso, apesar da sinonímia, preferimos a expressão educação corporal em vez de educação do corpo. Para nós, a educação corporal guarda similaridade com a noção de educação physica (PAIVA, 2003) no sentido de ocorrer em toda a sociedade, não sendo restrita a escola. E difere dela por não possuir uma teoria, estando em aberto para atribuírem sentidos e significados a ela.

Por fim, como um vislumbre do novo cenário, a educação física escolar assume, então, a tarefa precípua de selecionar na cultura um conjunto de ações e pensamentos que irá Ihe compor. Sua especificidade é consonante com seu tempo histórico, e por isso varia. $E$ isso fica claro no século $X X$ ao observamos o predomínio da ginástica, depois do esporte, uma hegemonia do paradigma da saúde, o movimento renovador valorizando outras práticas corporais, e, no século $\mathrm{XXI}$, um amalgama disso tudo. Com algumas práticas ainda mantendo o predomínio, mas por critérios sociais e políticos (e não epistemológicos ou ontológicos).A tarefa da educação física deixaria de ser uma busca por seus fundamentos ou ontologia, mas o conjunto de ações e pensamentos mais profícuos para a realização da educação corporal. Não precisaríamos buscar o denominador comum entre a plasticidade da bailarina em seus passos e a força bruta do levantador de pesos.

\section{CONSIDERAÇÕES FINAIS}

Oferecer um esboço do assunto como fizemos implica em reconhecer que outras questões conectadas para um maior enriquecimento de sua apresentação não puderam ser aqui tratadas. E, apesar de termos sido muito pontuais, visto termos lidado com um vocabulário próprio da filosofia analítica estadunidense, enquanto nossa

12 Em textos como Solidariedade ou objetividade? e A ciência natural é um gênero natural? Rorty (1997) debate em detalhes a suposta distinção entre ciências naturais e humanas. 
tradição de estudos na educação (física) se aproxima mais da filosofia continental europeia, há uma série de conceitos implícitos e modos de abordar o assunto os quais apenas deixamos registrados nas referências e como são importantes suas leituras para melhor exploração das ideias.

De modo conciso, compreendemos o corpo em sua contingência, portanto fora do modelo explicativo sujeito-objeto e corpo-mente cartesiano e pós-kantiano, bem como fora do modelo representacionalista aparência-realidade, isto é, diferente dos que postulam um modo de conectar mente-corpo - com ou sem elementos mediadores - para resolver o dualismo, aqui não se postula a existência de um ingrediente extra, recorrendo apenas ao corpo para explicar nossa relação com o mundo.

Ao nosso ver, há proficuidade nessa noção, pelas seguintes justificativas: a) ao recusar esse dualismo, acaba também por recusar noções essencialistas e reducionistas, abrindo espaço para um tratamento holístico e historicista; b) adotar o seu historicismo requer ver o desenvolvimento do corpo como contingente, aberto, e não dotado de um fim teleológico (com reminiscências teológicas ${ }^{13}$ ). As razões para o corpo assumir as suas atuais configurações ou receber um determinado tratamento é, basicamente, sociológica; c) tal perspectiva retira o corpo de sua posição subalterna em relação a mente, tal como preconizada por Descartes e outros, sem cair no oposto que o hiperboliza; d) para a educação física, é a possibilidade de diversificar a conversação sobre o corpo e as ações pedagógicas, evitando o enclausuramento epistemológico.

Apesar de se mostrar promissora, tal noção precisa ser efetivamente utilizada e experimentada para vermos e avaliarmos as consequências. De início pode até se mostrar dificultoso, pois a proposta de alterar um vocabulário habituado com a separação entre corpo e mente, além da separação entre mundo das aparências e mundo real, pode, temporariamente, nos deixar sem ferramentas para lidar com algumas questões. Pensamos que, como Rorty mostra, uma ferramenta efetivamente nova, não é aquela que de partida sabemos usar, mas que paulatinamente atribuímos significados e usos.

\section{REFERÊNCIAS}

ALMEIDA, Felipe Quintão; VAZ, Alexandre Fernandez. Richard Rorty e a Filosofia da Educação: uma análise da recepção marxista. Educação \& Realidade, v. 38, n. 1, p. 249270, jan./mar. 2013.

APPIAH, Kwame Anthony. Introdução à filosofia contemporânea. Petrópolis, RJ: Vozes, 2006.

BETTI, Mauro. Educação física escolar: ensino e pesquisa-ação. ljuí, RS: Ed. Unijuí, 2009.

13 Almeida e Vaz (2013), considerando os escritos de Rorty, sugerem ver o "afã realista presente na inflexão ontológica [da educação física] como a versão iluminista do ímpeto religioso de se curvar perante um poder não humano (desse modo, como uma herança do monoteísmo)". 
BRACHT, Valter. Educação física \& ciência: cenas de um casamento (in)feliz. ljuí: Ed. Unijuí, 1999a.

BRACHT, Valter. A constituição das teorias pedagógicas da educação física. Cadernos Cedes, ano XIX, n. 48, p. 69-88, ago. 1999b.

GHIRALDELLI JÚNIOR, Paulo. Neopragmatismo, Escola de Frankfurt e Marxismo. Rio de Janeiro: DP\&A, 2001.

HOUAISS, Antônio. Dicionário eletrônico Houaiss da língua portuguesa - versão monousuário 3.0. Rio de Janeiro: Objetiva, 2009.

ORTEGA, Francisco. O corpo incerto: corporeidade, tecnologias médicas e cultura contemporânea. Rio de Janeiro: Garamond, 2008.

PAIVA, Fernanda Simone Lopes de. Sobre o pensamento médico-higienista oitocentista e a escolarização: condições de possibilidade para o engendramento do campo da educação física no Brasil. 2003. 451f. Tese (Doutorado em Educação) Programa de Pós-Graduação em Educação, Universidade Federal de Minas Gerais, Belo Horizonte, 2003.

RORTY, Richard. A filosofia e o espelho da natureza. Rio de Janeiro: Relume-Dumará, 1994.

RORTY, Richard. Objetivismo, relativismo e verdade. Rio de Janeiro: Relume-Dumará, 1997.

RORTY, Richard. Verdade e progresso. Barueri: Manole, 2005.

RORTY, Richard. Contingências, ironia e solidariedade. São Paulo: Martins, 2007.

RORTY, Richard. Filosofia como política cultural. São Paulo: Martins Fontes, 2009.

SANT'ANNA, Denise Bernuzzi de. É possível realizar uma história do corpo? In: SOARES, Carmen Lúcia. Corpo e história. 3. ed. Campinas, SP: Autores Associados, 2006.

SAVIANI, Dermeval. Pedagogia histórico-crítica: primeiras aproximações. 9. ed. Campinas, SP: Autores Associados, 2005.

SILVA, Ana. Márcia. A natureza da physis humana: indicadores para o estudo da corporeidade. In: SOARES, Carmen Lúcia. (org.). Corpo e história. 4. ed. Campinas, SP: Autores Associados, 2011. p. 25-41

SILVA FILHO, Waldomiro José da. Davidson, a Metáfora e os Domínios do Literal. Utopía y Praxis Latinoamericana, v. 6, n. 15, p. 30-43, 2001.

SILVA, Heraldo Aparecido. A filosofia da educação de Richard Rorty: epistemologia, conversação, redescrições, narrativas e as funções da educação. Educação e Filosofia, v. 26, n. 52, p. 509-526, jul./dez. 2012.

SOARES, Carmen Lúcia. Educação física: raízes europeias e Brasil. 5. ed. rev. Campinas, SP: Autores Associados, 2012.

SOARES, Carmen Lúcia. Educação do corpo. In: GONZÁLEZ, Fernando Jaime; FENSTERSEIFER, Paulo Evaldo. Dicionário crítico de Educação Física. 3. ed. rev. e ampl. ljuí: Ed. Unijuí, 2014. p. 219-225. 